\title{
Mathematical self-concept among prospective teachers
}

\author{
Johannis Takaria ${ }^{1}$, Anderson Leonardo Palinussa ${ }^{2}$ \\ ${ }^{1}$ Department of Primary Education, Pattimura University, Indonesia \\ ${ }^{2}$ Department of Mathematics Education, Pattimura University, Indonesia
}

\begin{tabular}{l}
\hline \hline Article Info \\
\hline Article history: \\
Received Jan 4, 2020 \\
Revised Jul 21, 2020 \\
Accepted Sep 12, 2020 \\
\hline
\end{tabular}

Keywords:

Collaborative mind-mapping

Mathematics self-concept

Prospective teachers

\begin{abstract}
Mathematical self-concept (MS-C) is an important construct that prospective mathematics teachers must have in mathematics learning. The aim of the research was to analyze the increase of MS-C of prospective mathematics teachers. The research was quasi-experimental with the design of one group pretest-posttest. The results showed that for prospective teachers, MS-C increased in the medium category while the MS-C indicators achieved in the medium and low categories. The increase of MS-C is due to the effectiveness of collaborative mind mapping (CMM) learning strategy and the process of strengthening MS-C capacity of prospective teachers. The CMM facilitates prospective teachers to construct creative ideas through structured collective ideas that support the increase of MS-C among prospective teacher.
\end{abstract}

This is an open access article under the CC BY-SA license.

\section{Corresponding Author:}

Anderson Leonardo Palinussa,

Department of Mathematics Education,

Pattimura University,

Poka, Tlk. Ambon, Kota Ambon, Maluku, Indonesia.

Email: palinussaandersonl@gmail.com

\section{INTRODUCTION}

The control range of the Maluku region is a problem for high school graduates in the border areas to continue their studies in higher education in Ambon city. This problem needs for a solution by implementing learning programs for disadvantaged, outermost, and leading regions in the border areas in Maluku province. The goal is to improve the quality of human resources in the Aru island district. The area requires optimal teacher resources, both quantity and quality. The study program outside the main campus (SPOMC) in Pattimura University is one of alternative solutions to answer the educational challenges faced by students to continue their studies in higher education. Aru island district is located in the border area with Australia. Real conditions in the field prove that many teachers and students spend time at sea rather than learning to develop potential for present and future lives. The average community lives on the coast. Research related to selfconcept, especially MS-C in the border areas has not been widely developed [1]. The prospective teachers in lectures come with different mindsets and abilities. The differences have an impact on students' MS-C in learning. Early studies identified; most prospective teachers have low MS-Cs so that it needs optimal reinforcement. Students' anxiety before joining mathematics learning becomes an important problem that needs solution. Another problem is that students have difficulty completing mathematical tasks. Students are of the view that there are limitations to their mathematics abilities. This view influences motivation, and achievement of mathematics learning outcomes [2].

Mathematical anxiety and students' views on self-limitation show negative self-concepts [3]. Selfconcept is an important construct in education, related to individual academic achievement [4]. The view of the self-inability about the hope of achieving success and self-confidence in learning also shows negative 
self-concept. It has an impact on learning motivation and excessive anxiety before taking lessons [5]. Selfconcept is a multi-dimensional process that refers to the individual's self-perceptions and is related to a number of characteristics possessed by oneself, such as physical appearance, performance, self-ability, goals, values, and self-esteem [6].

Self-concept greatly influences how students feel about themselves, their mathematics ability, and decisions made regarding education that are manifested through students' academic achievement in learning [7]. Academic self-concepts are related to academic achievement and are defined as beliefs and feelings or individual intellectual perceptions of abilities possessed [8]. Academic self-concept is selfperception and leads more to scholastic competence, not attitude [9]. Self-concept refers to someone's perception of themselves in relation to their academic achievement [10]. Individual academic self-concepts have a direct and indirect effect on academic achievement, an increase in academic self-concepts leads to an increase in academic achievement and vice versa, high academic self-concepts directly influence academic achievement better because of the positive self-concepts students have can trigger them to be actively involved in constructing creative ideas in mathematics learning [11]. To trigger an increase of MS-C on prospective teachers, special treatment is important to form positive students' self-concepts in mathematics learning. MS-C refers to perceptions or beliefs in ability to do well in mathematics or beliefs in learning mathematics [12]. MS-C is a strong indicator of school performance, education and employment choices [13]. MS-C has a positive relationship with students' mathematics achievement [14]. Students are more confident about mathematical abilities because they have high positive self-concepts [15]. Social support of parents plays an important role in predicting MS-C [16]. Mathematical self-concepts refer to students' perceptions of their own capacity and level of performance in mathematics [17]. MS-C can increase students' confidence [18]. The results of the study indicate that MS-C is important for prospective teachers to be actively involved in solving mathematical problems.

Students' MS-C can be improved through collaborative problem-solving learning model. Collaborative learning involves students to dedicate themselves to work in groups by setting projections of work together and presenting new knowledge through collaboration [19]. Students in collaborative groups learn to construct knowledge together as a structure in thinking mathematically. Effective learning occurs when individuals learn from others rather than self-study [20], one of which is collaborative learning. The collaborative learning approach is a form of creative learning and is done by presenting contextual learning media that can trigger students to work actively as a whole in conveying creative ideas [21]. Creative learning is characterized by submitting challenging questions, making connections and seeing relationships, imagining what might happen, exploring creative ideas, having many options in solving problems, having critical ideas from concrete actions, and generating ideas to achieve optimal results [22].

Collaborative learning makes students active in learning, because of the emphasis on free individual thinking and their ability to solve problems [23]. The stages in collaborative learning are engagement, exploration, transformation, presentation and reflection [24]. Exploration and reflection are important stages in forming MS-C of prospective teachers. Reflection is done to evaluate the strengths and weaknesses of students during the collaboration process. The process of collaboration, demonstration, and understanding of the material learned can be done through mind mapping strategies and implemented through group learning $[25,26]$. Mind mapping is an application that gives meaning to understanding information in a simple way [27]. This research combines collaborative learning with mind mapping settings that is called Collaborative Mind Mapping (CMM). CMM can trigger students to construct ideas together in solving mathematical problems [28]. Learning with the CMM strategy for prospective primary school teachers in the SPOMC in the Aru island district aims to increase students' MS-C and minimize negative MS-C, including: mathematical anxiety, self-perception of limited mathematics abilities, sensitivity to criticism, other people's views on ability mathematics, a negative self-view of the future. If negative MS-C can be minimized, there will be an increase in mathematics learning outcomes. Minimizing the negative MS-C of students takes time continuously and needs concrete actions to improve MS-C for prospective elementary school teachers in the SPOMC in Aru Regency, Maluku Province, Indonesia.

\section{RESEARCH METHOD}

The research was quasi-experimental employed design of one group pretest-posttest and involving 60 students of primary school teacher candidates as research subjects. The research design can be seen as follows [29].

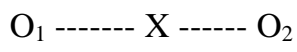


Note:

$\mathrm{O}_{1}$ : Pretest MS-C

$\mathrm{O}_{2}$ : Posttest MS-C

$\mathrm{X}$ : CMM Strategy and Strengthening of MS-C capacity

The study sample was 60 students of primary school teacher candidates in the fifth semester of the academic year 2017/2018. The sampling technique was done through purposive sampling. The aim was to find out the improvement of students' MS-C with consideration of the social background, culture, and location of students in the outermost areas, as well as the ability of students who varied at high, medium and low levels. The study was conducted for one semester (6 months) in the Mathematics Education course.

The Pretest Self-Concept scale (Pretest-MS-C) was used to measure the initial ability of students' MS-C before applying the CMM strategy and strengthening MS-C capacity. Another goal was to distribute students in collaborative groups according to the rules of forming ideal groups. After the CMM strategy was applied, Posttest self-concept (Postest-MS-C) was implemented. The MS-C scale before being distributed to the respondent was first validated by the expert and a statistical test was performed to see the validity and reliability. Fourty five items were distributed to respondents, and tests were conducted to check the validity of the MS-C scale with the help of SPSS ver-19, identified that 43 items were declared valid while 2 items were invalid, so 43 items of statements were used in the MS-C data collection process. The reliability test results obtained Cronbach's Alpha value of 0.93 in the very high category. The observation sheet was used to assess learning activities for both students and lecturers. At the end of the lesson interviews were conducted with students to explore more deeply the MS-C that is held by prospective teachers.

Ordinal MS-C data is converted to interval scale using the Method of Successive Interval (MSI). Ordinal data should be converted to interval data (for example with MSI). The purpose of which was to fulfill the data analysis requirements in parametric statistics [30]. The conversion data were analyzed using paired ttest samples. The results of the analysis were then described through stages: 1) Describing the results of research related to students' MS-C obtained through observation and interviews; 2) Analyzing of improvement of students' mathematical self-concepts using centralized N-gain [31, 32].

\section{RESULTS AND DISCUSSION}

Before the implementation of the CMM strategy and strengthening MS-C capacity, it was necessary to have pretest. It aimed to find out the initial mathematical self-concept of students. Pretest-SC and PostestSC were measured using a four-grade MS-C scale, in the categories: Strongly Agree, Agree, Disagree, and Strongly Disagree and include two main components, namely, the conceptual and attitude components outlined in five indicators: 1) Views of mathematics abilities and disabilities; 2) Mathematical attitude and self-confidence; 3) Self-sensitive; 4) Mathematics is important for the future; and 5) Other people's views on mathematics abilities.

\subsection{Strengthening the capacity of students' MS-C}

Before the learning process using the CMM strategy, the lecturer effectively identified MS-C problems by referring to the Pretest-SC results. Identification results were discussed during the brainstorming process to strengthen MS-C capacity based on identification of strengths and weaknesses. Based on the results of the identification, the lecturers grouped the MS-C problems experienced by students to be discussed in the sharing process between students and lecturers and students and peers. The goal was to get a solution to minimize the negative MS-C of students in learning. Figure 1 shows the systematic strengthening of MS-C capacity.

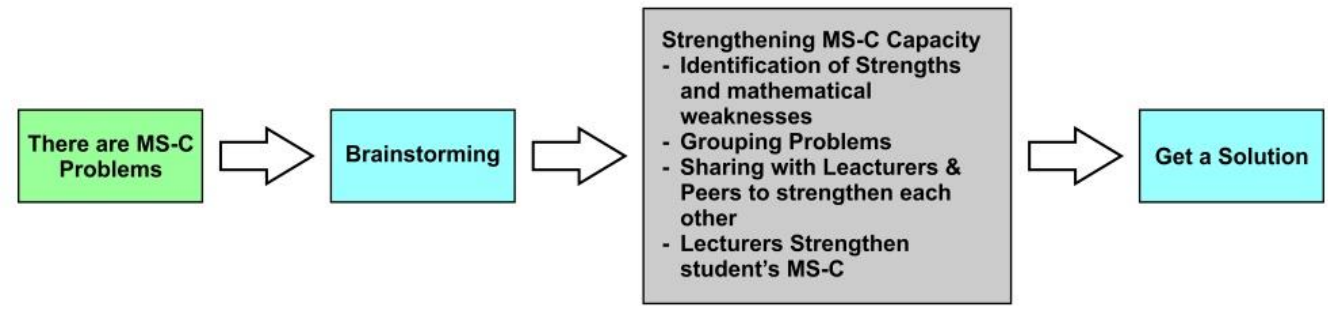

Figure 1. Systematics of students' MS-C capacity strengthening 


\subsection{CMM strategy implementation}

The increase of MS-C was measured after the CMM strategy was applied which was oriented to the effectiveness of students' interaction and strengthening MS-C capacity. Collaborative learning is a form of learning that involves intellectual efforts together to seek mutual understanding, solutions, meanings, and produce products based on mutual agreement [33]. Learning collaborative problem solving requires problems that are solved in groups and not only by individual abilities. This was due to a lack of experience from different individuals [34]. Collaborative learning is a learning strategy that requires students to be individually responsible, interact, and collaborate as a structure in developing ideas together. Students were encouraged to find a variety of opinions in mathematical problem solving. This study used collaborative strategies with five stages in learning: engagement, exploration, transformation, presentation and reflection. Figure 2 displays the CMM strategy.

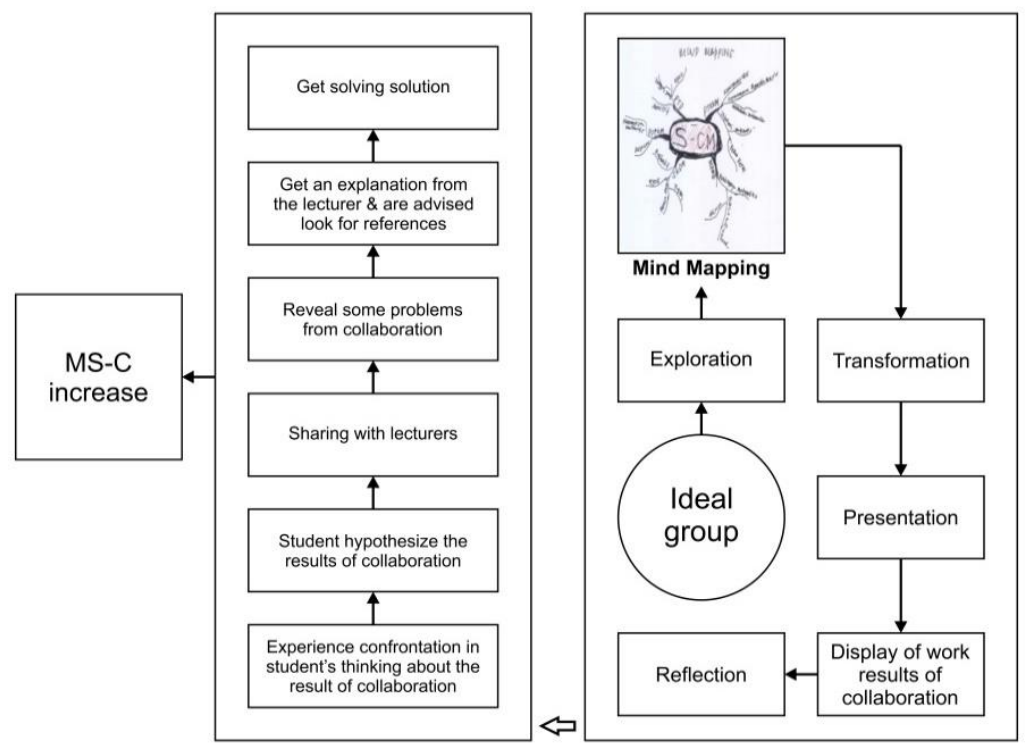

Figure 2. CMM strategy design

The CMM learning strategy in Figure 2 shows that students together could form collaborative groups freely by referring to the ideal group formation criteria. In the collaboration process, students individually explored creative ideas by making thought maps of mathematical ideas expressed in various creative ways. For the mind mapping process, the lecturer had provided an overview of how to design a mind map of the concepts learned. The results of the exploration of ideas were then transformed into groups to equate ideas that had been conceptualized. After an agreement on ideas together, the group interpreted the results of the collaboration by displaying the work. Each group visited each other and observed the work of other groups and asked questions about the results of collaboration. Each student in the group individually and collectively was responsible for answering each question from another group. At the end of the collaboration, reflection was carried out both individually and in groups. If there were problems that had not been resolved or were not in line with the expectations of the students, then brainstorming with the lecturer was carried out. All collaborative processes were carried out using observation sheets to observe the activities of students and lecturers in learning.

It was also identified that lecturers conducted interviews with several students to explore more deeply the problems faced by students. Motivation and direction were given by lecturers to strengthen the MS-C of students. Lecturers position themselves was as an active facilitator in aligning various opinions and providing solutions to the problems faced by each student when they were interacting, because MS-C can be improved by active interactions. Self-concept is not inherited from birth, but is developed or built by individuals through interaction with the socio-cultural environment [35]. Students' self-concepts can develop along with the maturity of students in lectures, where cognitive levels increase and their emotional level can be controlled. Adult development can be studied and analyzed through a dynamic, goals, orientation to be achieved, and the development of a value system, because it deals with cognitive and emotional processes [36, 37].

Int. J. Eval. \& Res. Educ. Vol. 9, No. 4, December 2020: 799 - 806 


\subsection{Test the difference in MS-C increase}

Before testing to see whether there was a difference in the increase in mathematical self-concept of prospective teachers before and after using the CMM strategy, it is necessary to test the normality and homogeneity of the data. Table 1 presents the results of the MS-C data normality and homogeneity test.

\begin{tabular}{lll} 
Table 1. Test for normality and homogeneity of MS-C data \\
\hline Kolmogorov-Smirnova & & Interpretation \\
\hline Pre_SC & 0.200 & Normal \\
Post_SC & 0.170 & Normal \\
Levene's test for equality of variances & \\
Pre_Post_SC & 0.185 & Homogen \\
\hline
\end{tabular}

Referring to Table 1 related to the normal and homogeneous test, it is obtained the value of Sig. Pre_SC and Post_SC (0.200 and 0.170) greater than 0.05 , so that group data is normally distributed. After fulfilling the normal assumptions, then the data homogeneity was tested using the Levene test, which resulted in the Sig. (0.185) greater than 0.05, so the data is homogeneous. After fulfilling the assumptions in the parametric test, the testing was done to see the difference in the increase of mathematical self-concept using the dependent sample t-test with the testing hypothesis:

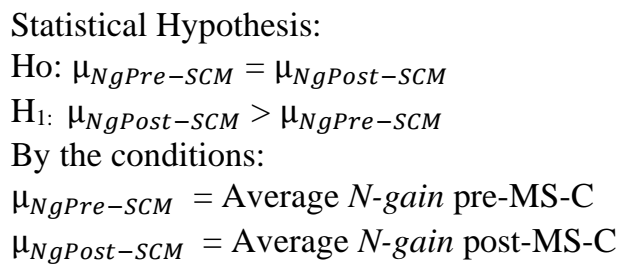

Research Hypothesis:

Ho: The increase in MS-C of students before and after using the CMM strategy is not different

$\mathrm{H}_{1}$ : The increase in students' MS-C after using the CMM strategy is better than before using CMM

Table 2 displays the results of the test for the difference in MS-C increase which was analyzed using the Paired sample t-test on the N-gain value obtained.

Table 2. Test the difference in MS-C increase

\begin{tabular}{|c|c|c|c|c|c|}
\hline & Self-concept Matema & & & & \\
\hline $\mathrm{N}$-gain $\langle\mathrm{g}>$ & $\begin{array}{l}\text { Test Type } \\
\text { Paired Sample t-test }\end{array}$ & $\begin{array}{l}\mathrm{t} \\
-9.818\end{array}$ & $\begin{array}{l}\text { Df } \\
59\end{array}$ & $\begin{array}{l}\text { sig } \\
0.000\end{array}$ & $\begin{array}{l}\text { Interpretation } \\
\mathrm{H} 1 \text { accepted }\end{array}$ \\
\hline
\end{tabular}

The results of the Paired Sample t-test in Table 2 shows that the Sig. (0.000) less than 0.05 so that the $\mathrm{H}_{1}$ decision is accepted. This means that the increase in students' MS-C after using the CMM strategy is better than before using CMM. The results of these statistical tests show that the CMM trategy is effective in increasing the MS-C of prospective teachers in the border area.

\subsection{Improvement of students' MS-C indicators}

To analyze the increase of students' MS-C indicators, it was used Post-SC with 43 items of statements both positive and negative that have been tested for validity and reliability. The increase in mathematical self-concepts was analyzed using N-gain, but for the purposes of analysis, the self-concept data which was ordinal type is converted to the interval scale using the Successful Interval Method (MSI). Table 3 presents an increase in MS-C indicators. 
Table 3. The increase of MS-C indicators

\begin{tabular}{|c|c|c|c|c|c|}
\hline Indicators & Sub Indicators & $\mathrm{N}$-gain & $\bar{X}_{N-\text { gain }}$ & $\bar{X}_{N-\text { gain }}(\%)$ & Category \\
\hline \multirow{5}{*}{$\begin{array}{l}\text { Views on } \\
\text { Mathematics } \\
\text { Capabilities \& } \\
\text { Disabilities }\end{array}$} & Understanding mathematics & 0.38 & \multirow{5}{*}{0.27} & \multirow{5}{*}{$27 \%$} & \multirow{5}{*}{ Low } \\
\hline & Mathematical communication skills & 0.26 & & & \\
\hline & Construction of mathematical ideas & 0.23 & & & \\
\hline & Mathematical problem-solving skills & 0.24 & & & \\
\hline & Understanding mathematical information & 0.23 & & & \\
\hline Mathematics is & Mathematics is Important for the Future & 0.38 & \multirow{3}{*}{0.31} & \multirow{3}{*}{$31 \%$} & \multirow{3}{*}{ Medium } \\
\hline Important for the & Become a Professional Mathematics Teacher & 0.24 & & & \\
\hline \multirow[t]{4}{*}{ Future } & Actively involved in the community & 0.32 & & & \\
\hline & Mathematical Self Confidence & 0.50 & \multirow{9}{*}{0.48} & \multirow{8}{*}{$48 \%$} & \multirow{8}{*}{ Medium } \\
\hline & Work on math assignments independently & 0.64 & & & \\
\hline & Hard worker & 0.52 & & & \\
\hline Mathematics Attitude & Responsible & 0.44 & & & \\
\hline \multirow[t]{6}{*}{ \& Confidence } & Mathematically Reflective opinions & 0.38 & & & \\
\hline & Solve math problems thoroughly & 0.46 & & & \\
\hline & Selfish & 0.32 & & & \\
\hline & Respect people's & 0.58 & & & \\
\hline & Mathematical anxiety & 0.22 & & \multirow{5}{*}{$28 \%$} & \multirow{5}{*}{ Low } \\
\hline & Sensitive to criticism & 0.24 & \multirow{4}{*}{0.28} & & \\
\hline \multirow[t]{3}{*}{ Self-Sensitivity } & Sensitive to praise & 0.29 & & & \\
\hline & Feel ignored by the lecturer & 0.27 & & & \\
\hline & Doubt about the work of mathematics & 0.38 & & & \\
\hline \multirow{4}{*}{$\begin{array}{l}\text { Other people's views } \\
\text { on mathematical } \\
\text { abilities }\end{array}$} & Have math skills & 0.41 & \multirow{3}{*}{0.37} & \multirow{3}{*}{$37 \%$} & \multirow{3}{*}{ Medium } \\
\hline & Don't have communication skills & 0.34 & & & \\
\hline & Undisciplined to work on independent tasks & 0.36 & & & \\
\hline & Total & & 0.34 & $34 \%$ & Medium \\
\hline
\end{tabular}

Table 3 shows that self-confidence and students' attitudes toward mathematics abilities can be increased by $48 \%$ in the medium category. Based on the results of the interview, it was revealed that during the process of exploration and transformation of ideas among students when collaborating, they exchanged information and gave reinforcement, so that they could develop MS-C prospective teachers. The CMM learning strategy triggered students to construct creative ideas through thought maps that were carried out and reached an increase of $24 \%$, but still in the low category. The results of observations show that students can provide varied answers to collaborative mathematics problems. The process of exploring and transforming ideas requires an MS-C that is strong in conveying the ideas of each individual when collaborating in groups. CMM learning strategy involves reflection as an important step in the collaboration process. Reflection can facilitate students in various levels of ability to know their weaknesses and strengths. By reflection, students can share experiences and provide mutual reinforcement, which has an impact on the development of students' MS-C. Argued that reflection can consider students' motivation, ideas raised, skills needed to learn in various situations, and can reflect obstacles in learning that will be gaps in knowledge and skills, and how students can manage them [38].

Through the observation sheet, it was found that there was a process of transforming ideas among students who needed courage in building effective communication and achieving an increase of $26 \%$. Effective communication was built through various opinions expressed by students in collaborative groups. Courage requires positive self-concepts in students. Positive students' MS-C made collaboration more meaningful, because the learning atmosphere became fun and flexible. This was shown through several things, namely: 1) students collectively created an atmosphere of collaboration to be effective and fun; 2) prospective teachers could explore ideas individually through a variety of ideas conceptualized through thought maps; 3) The CMM Strategy triggered students to exchange ideas to achieve an agreement; 4) each individual could demonstrate mathematical ability to work effectively and appreciate diversity in groups; 5) students built criticism and give each other positive responses flexibly; each individual carried out responsibilities well in completing mathematics tasks, even though there are some students who had not optimized their thinking abilities; and 6) students showed respect for peer opinions; students tend to still show personal selfishness, but with the direction of the lecturer, the attitude of the student's ego can be minimized.

The CMM strategy contributed positively to the increase in students' MS-C. Overall, students achieved MS-C increase in the medium category, while increase in the low and medium categories for the MS-C per-indicator. The achievement of increasing MS-C of students in the medium and low categories indicates that prospective teachers in the border area must be continuously provided assistance and strengthening of the MS-C capacity they have. The views on the difficulty of mathematics, anxiety, and mathematics self-confidence are important indicators that must be improved, because these indicators are the causes of the low increase in students' MS-C. Although MS-C increased in the low and medium categories, 
the CMM strategy and the strengthening of MS-C capacity were effective for use in mathematics learning, but it needed a relatively long time for optimal MS-C development. The increase of students' MS-C in learning is facilitated by strengthening MS-C capacity and the use of CMM learning strategies. One dimension of forming a self concept is colective self concept, referring to the collaborative process in which individuals are located [39, 40].

Individual self-concepts can be formed through processes in groups when interacting. Students' MS$\mathrm{C}$ can be improved through effective learning interactions. Lecturers can create an atmosphere and assumption of students towards their concepts, both positive and negative self-concepts. Professional lecturers should be able to bring up a positive self-concept of students by way of, 1) respecting students' opinions, 2) providing opportunities for students to ask questions, 3) triggering cognitive conflict among students, 4) giving praise with words that can motivate learning. MS-C of prospective primary school teachers should be able to adjust and change with the culture in which students are located. The mindset and attitude of students in learning must be adapted to the contextual problems of the local culture. These changes can affect the atmosphere and learning styles that are flexible and change the negative perspective of others through the abilities shown when interacting [41]. The optimal implementation of the CMM learning strategy can improve the MS-C of prospective elementary school teacher in the border areas in the Aru Islands, Maluku province, Indonesia.

\section{CONCLUSION}

Overall, prospective elementary school teacher has an increase of MS-C with an average achievement of improvement in the low category. MS-C per indicator increases in the medium and low categories. Increasing the MS-C of prospective elementary school teachers is due to the process of strengthening MS-C capacity and the effectiveness of creative learning using the CMM strategy. The CMM strategy can facilitate students to share mathematical ideas creatively through a collaborative process carried out in structured collectivity. In the collaborative process, students give a positive response to learning with the CMM strategy. This response has implications on the increasing MS-C indicators on prospective teachers. To increase the MS-C, it requires a continuous process. This conclusion recommends relevant research to be carried out by using other creative learning strategies in measuring motivation, selfproficiency, and other aspects of attitudes, as well as mathematics learning outcomes.

\section{REFERENCES}

[1] V. Kolossov and J. Scott, "Selected conceptual issues in border studies," Belgeo, vol. 2013, no. 1, pp. 1-19, 2013.

[2] Y. Lai, et al., "Effects of mathematics anxiety and mathematical metacognition on word problem solving in children with and without mathematical learning difficulties," PLoS One, vol. 10, no. 6, pp. 1-19, 2015.

[3] M. Paechter, D. Macher, K. Martskvishvili, S. Wimmer, and I. Papousek, "Mathematics Anxiety and statistics anxiety. Shared but also unshared components and antagonistic contributions to performance in statistics," Front. Physiol., vol. 8, no. July, pp. 1-13, 2017.

[4] J. Xu, "Reciprocal effects of homework self-concept, interest, effort, and math achievement," Contemp. Educ. Psychol., vol. 55, pp. 42-52, Oct. 2018.

[5] A. D. Goldman and A. M. Penner, "Exploring international gender differences in mathematics self-concept," Int. J. Adolesc. Youth, vol. 21, no. 4, pp. 403-418, 2016.

[6] A. Gregory, R. P. Hastings, and H. Kovshoff, "Academic self-concept and sense of school belonging of adolescent siblings of autistic children," Res. Dev. Disabil., vol. 96, no. January, pp. 37-45, 2020.

[7] M. M. Hammoudi, "Measurement of students' mathematics motivation and self-concept at institutions of higher education: evidence of reliability and validity," Int. J. Math. Educ. Sci. Technol., vol. 51, no. 1, pp. 1-24, 2019.

[8] I. B. Wolter and B. Hannover, "Gender role self-concept at school start and its impact on academic self-concept and performance in mathematics and reading," Eur. J. Dev. Psychol., vol. 13, no. 6, pp. 681-703, 2016.

[9] M. Seaton, P. Parker, H. W. Marsh, R. G. Craven, and A. S. Yeung, "The reciprocal relations between self-concept, motivation and achievement: Juxtaposing academic self-concept and achievement goal orientations for mathematics success," Educ. Psychol., vol. 34, no. 1, pp. 49-72, 2014.

[10] J. Fang, X. Huang, M. Zhang, F. Huang, Z. Li, and Q. Yuan, "The big-fish-little-pond effect on academic selfconcept: A meta-analysis," Front. Psychol., vol. 9, no. August, pp. 1-11, 2018.

[11] L. Holopainen, A. Taipale, and H. Savolainen, "Implications of Overlapping Difficulties in Mathematics and Reading on Self-Concept and Academic Achievement," Int. J. Disabil. Dev. Educ., vol. 64, no. 1, pp. 88-103, 2017.

[12] S. Colmar, G. A. D. Liem, J. Connor, and A. J. Martin, "Exploring the relationships between academic buoyancy, academic self-concept, and academic performance: a study of mathematics and reading among primary school students," Educ. Psychol., vol. 39, no. 8, pp. 1068-1089, 2019.

[13] G. Nagy, H. M. G. Watt, J. S. Eccles, U. Trautwein, O. Lüdtke, and J. Baumert, “The Development of Students' Mathematics Self-Concept in Relation to Gender: Different Countries, Different Trajectories?" J. Res. Adolesc., vol. 20, no. 2, pp. 482-506, 2010. 
[14] J. Wang and E. Lin, "An alternative interpretation of the relationship between self-concept and mathematics achievement: Comparison of Chinese and US students as a context," Eval. Res. Educ., vol. 21, no. 3, pp. 154-174, 2008.

[15] W. Luo, D. Hogan, L. S. Tan, B. Kaur, P. T. Ng, and M. Chan, "Self-construal and students' math self-concept, anxiety and achievement: An examination of achievement goals as mediators," Asian J. Soc. Psychol., vol. 17, no. 3, pp. 184-195, 2014.

[16] C. Su and M. Hynie, "Effects of life stress, social support, and cultural norms on parenting styles among mainland Chinese, European Canadian, and Chinese Canadian immigrant mothers," J. Cross. Cult. Psychol., vol. 42, no. 6, pp. 944-962, 2011.

[17] H. Salmi, M. P. Vainikainen, and H. Thuneberg, "Mathematical thinking skills, self-concept and learning outcomes of 12-year-olds visiting a mathematics science centre exhibition in Latvia and Sweden," J. Sci. Commun., vol. 14, no. 4, pp. 1-19, 2015.

[18] R. Sheldrake, "Differential predictors of under-confidence and over-confidence for mathematics and science students in England," Learn. Individ. Differ., vol. 49, pp. 305-313, Jul. 2016.

[19] T. Ryberg, J. Davidsen, and V. Hodgson, "Understanding nomadic collaborative learning groups," Br. J. Educ. Technol., vol. 49, no. 2, pp. 235-247, 2018.

[20] E. Retnowati, P. Ayres, and J. Sweller, "Collaborative learning effects when students have complete or incomplete knowledge," Applied Cognitive Psychology, vol. 32, no. 6, pp. 681-692, 2018.

[21] L. A. Fenge, "Enhancing the doctoral journey: The role of group supervision in supporting collaborative learning and creativity," Stud. High. Educ., vol. 37, no. 4, pp. 401-414, 2012.

[22] S. M. Ritter and N. Mostert, "Enhancement of Creative Thinking Skills Using a Cognitive-Based Creativity Training,” J. Cogn. Enhanc., vol. 1, no. 3, pp. 243-253, 2017.

[23] C. Rosé, et al., "Analyzing collaborative learning processes automatically: Exploiting the advances of computational linguistics in computer-supported collaborative learning," Int. J. Comput. Collab. Learn., vol. 3, no. 3, pp. 237-271, 2008.

[24] N. Davidson and C. H. Major, "Boundary Crossings: Cooperative Learning, Collaborative Learning, and ProblemBased Learning," J. Excell. Coll. Teach., vol. 25, no. 3-4, pp. 7-55, 2014.

[25] A. Rosciano, "The effectiveness of mind mapping as an active learning strategy among associate degree nursing students," Teach. Learn. Nurs., vol. 10, no. 2, pp. 93-99, 2015.

[26] J. R. Batlolona and H. F. Souisa, "Problem based learning: Students' mental models on water conductivity concept," Int. J. Eval. Res. Educ., vol. 9, no. 2, pp. 269-277, 2020.

[27] E. A. McCrea and S. J. Lorenzet, "Mind Mapping: An Experiential Approach to Syllabus Review," Organ. Manag. J., vol. 15 , no. 1 , pp. 35-43, 2018.

[28] H. Stokhof, B. de Vries, T. Bastiaens, and R. Martens, "Using Mind Maps to Make Student Questioning Effective: Learning Outcomes of a Principle-Based Scenario for Teacher Guidance," Res. Sci. Educ., vol. 50, pp. 1-23, 2018.

[29] R. Okano, et al., "The Use and Int," J Am Med Inf. Assoc., vol. 13, no. 1, pp. 16-23, 2006.

[30] W. L. Hays, Quantification in psychology. Prentice Hall: New Delhi, 1967.

[31] R. R. Hake, "Interactive-engagement versus traditional methods: A six-thousand-student survey of mechanics test data for introductory physics courses," Am. J. Phys., vol. 66, no. 1, pp. 64-74, 1998.

[32] D. E. Meltzer, "The relationship between mathematics preparation and conceptual learning gains in physics: A possible 'hidden variable' in diagnostic pretest scores," Am. J. Phys., vol. 70, no. 12, pp. 1259-1268, 2002.

[33] C. N. Loes, K. C. Culver, and T. L. Trolian, "How Collaborative Learning Enhances Students' Openness to Diversity," J. Higher Educ., vol. 89, no. 6, pp. 935-960, 2018.

[34] C. N. Loes and E. T. Pascarella, "Collaborative Learning and Critical Thinking: Testing the Link," J. Higher Educ., vol. 88, no. 5, pp. 726-753, 2017.

[35] S. Zhao, S. Grasmuck, and J. Martin, "Identity construction on Facebook: Digital empowerment in anchored relationships," Comput. Human Behav., vol. 24, no. 5, pp. 1816-1836, 2008.

[36] E. Wood and H. Hedges, "Curriculum in early childhood education: critical questions about content, coherence, and control," Curric. J., vol. 27, no. 3, pp. 387-405, 2016.

[37] M. Leasa, A. D. Corebima, Ibrohim, and H. Suwono, "Emotional intelligence among auditory, reading, and kinesthetic learning styles of elementary school students in Ambon-Indonesia," Int. Electron. J. Elem. Educ., vol. 10, no. 1, pp. 83-91, 2017.

[38] M. Leasa, M. Talakua, and J. R. Batlolona, "The development of a thematic module based on Numbered Heads Together (NHT) cooperative learning model for elementary students in Ambon, Moluccas-Indonesia," New Educ. Rev., vol. 46, no. 4, pp. 174-185, 2016.

[39] N. R. Boyer, P. A. Maher, and S. Kirkman, "Transformative Learning in Online Settings: The Use of Self-Direction, Metacognition, and Collaborative Learning," J. Transform. Educ., vol. 4, no. 4, pp. 335-361, 2006.

[40] K. Scager, J. Boonstra, T. Peeters, J. Vulperhorst, and F. Wiegant, "Collaborative learning in higher education: Evoking positive interdependence," CBE Life Sci. Educ., vol. 15, no. 4, pp. 1-9, 2016.

[41] A. A. Anderson, et al., "Exploring the role of task performance and learning style on prefrontal hemodynamics during a working memory task," PLoS One, vol. 13, no. 6, pp. 1-16, 2018. 